\title{
Pelatihan Pengolahan Data Penelitian Berbasis Software JASP dan SPSS bagi Mahasiswa FKIP Universitas Mulawarman Kalimantan Timur
}

\author{
Didik Cahyono*1, Naheria², Muhammad Sukron Fauzi ${ }^{3}$ \\ 1,2,3Program Studi Pendidikan Jasmani, Universitas Mulawarman, Indonesia \\ *e-mail: didikcahyono86@gmail.com ${ }^{1}$, naheria@fkip.unmul.ac.id ${ }^{2}{ }_{\text {sukronfauzi950@yahoo.com }}^{3}$
}

\begin{abstract}
Abstrak
Sebagian besar mahasiswa yang kesulitan melakukan analisis data beranggapan bahwa untuk dapat menggunakan program JASP mereka harus Mengikuti pelatihan terlebih dahulu yang pastinya membutuhkan dana lebih untuk membayar biaya pelatihan tersebut. Selain daripada itu, walaupun mereka mempunyai program aplikasi JASP, namun mereka tidak mengetahui cara untuk menginstal maupun mengoperasikan program tersebut pada laptop mereka. Selain daripada itu, proses pengolahan data sebagai langkah pengujian hipotesis penelitian membutuhkan penguasaan dari berbagai jenis dan komponen analisis. Untuk itu perlu dilaksanakan pelatihan mengenai analisis data hasil penelitian menggunakan program JASP agar dapat membantu memudahkan mahasiswa dalam menganalisis data. Metode kegiatan ini berupa pelatihan dan pendampingan kepada mahasiswa Program Studi Pendidikan Jasmani Fakultas Keguruan dan Ilmu Pendidikan Universitas Mulawarman. Mahasiswa semester akhir dibimbing untuk menerapkan hasil pelatihan dalam rangka meningkatkan kemampuan mahasiswa dalam melakukan penelitian dan pengolahan data statistik. Hasil post test yang sudah di lakukan bahwa peserta kegiatan pelatihan sebagian besar (88,9\%) mampu memahami dan menganalisa fungsi program JASP dan SPSS dengan baik.
\end{abstract}

Kata kunci: Data Penelitian, JASP, Pengolahan Data, SPSS

\begin{abstract}
Based on the results of the author's interview with several students who are compiling their final project at the Physical Education Study Program, Faculty of Teacher Training and Education, Mulawarman University, it was found that most students who had difficulty doing data analysis thought that to be able to use the JASP program they had to undergo training first, which is definitely need more funds to pay for the training costs. Besides that, even though they have a JASP application program, they don't know how to install or operate the program on their laptops. Apart from that, the data processing process as a step of testing research hypotheses requires mastery of various types and components of analysis. For this reason, it is necessary to carry out training on data analysis of research results using the JASP program in order to help facilitate students in analyzing data. The method of this activity is in the form of training and mentoring for students of the Physical Education Study Program, Faculty of Teacher Training and Education, Mulawarman University. Final semester students are guided to apply the results of the training in order to improve students' abilities in conducting research and processing statistical data. The results of the post test that have been carried out show that most of the participants in the training activities (88.9\%) are able to understand and analyze the functions of the JASP and SPSS programs well
\end{abstract}

Keywords: Data Processing, JASP, Research Data, SPSS

\section{PENDAHULUAN}

Perguruan Tinggi merupakan suatu jenjang pendidikan yang dijalani oleh seseorang setelah selesai menempuh pendidikan sekolah menengah atas, didalam perguruan tinggi seseorang akan mempelajari suatu disiplin ilmu yang secara spesifik mempelajari ilmu yaitu salah satunya mempelajari ilmu pada program studi pendidikan jasmani (Kamus Besar Bahasa Indonesia, 2012). Selain itu dengan menempuh pendidikan diperguruan tinggi mahasiswa juga mendapatkan ilmu serta wawasan pengetahuan yang didapatkan dikehidupan sehari-hari dan berguna untuk masa depan. Bagi mahasiswa tingkat akhir yaitu pada mahasiswa semester enam, aplikasi statistika banyak digunakan dalam metode penelitian karena penelitian merupakan serangkaian kegiatan yang meliputi pengumpulan data, pengolahan data, analisis data, menginterpretasikan, dan menarik kesimpulan dari sekumpulan data yang kemudian ditulis secara lengkap dan sistematis. Semua kegiatan penelitian yang sifatnya bertahap tersebut harus 
dilakukan dengan cara ilmiah sehingga dapat dipertanggungjawabkan kepada semua pihak. Dalam pembuatan karya ilmiah, mahasiswa tingkat akhir seringkali memiliki ketakutan dalam hal pengolahan data statistik. Mereka menganggap bahwa pengolahan data statistik merupakan hal yang sulit sehingga sebagian mahasiswa memilih untuk menyerahkan pengolahan data penelitiannya kepada penyedia jasa pengolahan data. Hal ini tentu sangat disayangkan mengingat kemampuan pengolahan data statistik akan mempengaruhi kualitas kemampuan interpretasi hasil dan kualitas karya ilmiah tersebut. Sebagian besar orang beranggapan bahwa statistik adalah ilmu yang sulit, penuh dengan rumus-rumus rumit yang memerlukan ketelitian dan kecermatan dalam perhitungannya. Namun seiring dengan kemajuan yang pesat dalam bidang teknologi, muncul berbagai program komputer yang dirancang khusus untuk membantu pengolahan data statistik. Pengolahan data statistik menjadi jauh lebih mudah dan menyenangkan tanpa mengurangi ketepatan hasil outputnya.

\subsection{Pemanfaatan Teknologi}

Pemanfaatan teknologi informasi dan komunikasi untuk pendidikan dapat dilaksanakan dalam berbagai bentuk sesuai dengan fungsinya dalam pendidikan (Firmansyah, 2018). Berbagai aplikasi teknologi informasi dan komunikasi sudah tersedia untuk masyarakat dan sudah siap menanti untuk dimanfaatkan secara optimal untuk keperluan pendidikan (Nugroho, 2018) Statistika merupakan ilmu yang berkenaan dengan data, sedang statistik adalah data, informasi, atau hasil penerapan algoritma statistika pada suatu data (Suharsimi, 2006). Terdapat bermacammacam teknik statistik yang dapat digunakan dalam penelitian khususnya dalam pengujian hipotesis (Sugiono, 2010). Salah satu program analisis data yang dapat dipakai dalam analisis data kuantitatif adalah Program JASP.

\subsection{JASP}

Program JASP merupakan program yang dikhususkan untuk mengolah data statistik. Program ini dikenal sangat handal dalam membantu para peneliti untuk melakukan uji dan analisis statistic (Panjaitan \& Firmansyah, 2018). Dari temuan Tim penulis di lapangan, masih banyak mahasiswa Fakultas Keguruan dan Ilmu Pendidikan Program studi pendidikan jasmani Universitas Mulawarman yang belum bisa menggunakan program JASP dalam mengolah data penelitian terkait penyelesaian tugas akhir / skripsi, apabila tugas akhir mereka menggunakan jenis penelitian kuantitatif. Hal ini mengakibatkan mereka lebih memilih menggunakan jasa pengolah data karena mereka tidak memahami cara penggunaan program JASP maupun program pengolahan data lainnya.

Berdasarkan hasil wawancara penulis kepada beberapa mahasiswa yang sedang menyusun tugas akhir di Program Studi Pendidikan Jasmani Fakultas Keguruan dan Ilmu Pendidikan Universitas Mulawarman, diperoleh bahwa sebagian besar mahasiswa yang kesulitan melakukan analisis data beranggapan bahwa untuk dapat menggunakan program JASP mereka harus Mengikuti pelatihan terlebih dahulu yang pastinya membutuhkan dana lebih untuk membayar biaya pelatihan tersebut. Selain daripada itu, walaupun mereka mempunyai program aplikasi JASP, namun mereka tidak mengetahui cara untuk menginstal maupun mengoperasikan program tersebut pada laptop mereka. Selain daripada itu, proses pengolahan data sebagai langkah pengujian hipotesis penelitian membutuhkan penguasaan dari berbagai jenis dan komponen analisis. Untuk itu perlu dilaksanakan pelatihan mengenai analisis data hasil penelitian menggunakan program JASP agar dapat membantu memudahkan mahasiswa dalam menganalisis data. Mahasiswa yang akan menyusun tugas akhir pasti akan sangat terbantu dengan adanya pelatihan JASP sehingga mahasiswa sangat antusias mengikuti pelatihan olah data penelitian. Dengan antusiasme yang tinggi dalam mengikuti pelatihan, maka akan berdampak positif terhadap keberhasilan dan kelulusan mahasiswa di program studi pendidikan jasmani fakultas keguruan dan ilmu pendidikan universitas mulawarman. Pelatihan JASP juga dapat membantu meningkatkan pengetahuan dan pemahaman mahasiswa tentang ilmu statistika dan dapat mengoperasikan software olah data penelitian. 


\subsection{Solusi yang di tawarkan}

Tim pengabdian program studi pendidikan jasmani fakultas keguruan dan ilmu pendidikan merasa terpanggil untuk dapat melaksanakan pengabdian masyarakat ini karena merasa bertanggung jawab atas keberhasilan mahasiswa dalam pendidikan dengan pemanfaatan teknologi, yang akhirnya dapat digunakan dalam penyusunan tugas akhir, dan juga dalam dunia kerja mereka nantinya dari kondisi tersebut, maka tim pengabdian bertujuan untuk mengadakan pengabdian kepada masyarakat sebagai bagian dari Tri Dharma Perguruan Tinggi berupa pelatihan dasar program JASP bagi mahasiswa semester VI (enam) Fakultas Keguruan dan Ilmu Pendidikan Universitas Mulawaman untuk meningkatkan kemampuan mahasiswa dalam menganalisa dan menginterpretasi data.

\section{METODE}

Metode kegiatan ini berupa pelatihan dan pendampingan kepada mahasiswa Program Studi Pendidikan Jasmani Fakultas Keguruan dan Ilmu Pendidikan Universitas Mulawarman. Mahasiswa semester akhir dibimbing untuk menerapkan hasil pelatihan dalam rangka meningkatkan kemampuan mahasiswa dalam melakukan penelitian dan pengolahan data statistik. Berikut ini adalah tahapan pelatihan yang dilakukan:

\subsection{Tahap Persiapan}

1. Survei (Pemilihan Lokasi)

2. Penyusunan bahan/materi pelatihan, meliputi: makalah dan modul untuk kegiatan pelatihan.

\subsection{Tahap Pelaksanaan}

Pelatihan Tahap pelaksanaan pelatihan dilakukan persiapan. Dalam tahap ini dilakukan pertama, penjelasan tentang teori statistik, sesi pelatihan ini menitikberatkan pada pemberian penjelasan statistik dan penggunaannya yang tepat sesuai permasalahan; kedua, sesi pelatihan yang menitikberatkan pada kemampuan aplikasi program statistik melalui aplikasi JASP Metode Pelatihan Untuk melaksanakan kegiatan tersebut digunakan beberapa metode pelatihan, yaitu: Presentasi dan Tanya Jawab, Metode ini dipilih untuk menjelaskan tentang materi statistik deskriptif dan dasar-dasar pengolahan data statistik, regresi linear dan analisis korelasi. Metode tanya jawab penting bagi para peserta pelatihan, baik disaat menerima penjelasan tentang teori serta saat mempraktekkannya.

\subsection{Demonstrasi}

Metode demonstrasi ini penting bagi para peserta pelatihan, mendemonstrasi materi yang telah diperoleh menggunakan aplikasi JASP. Metode ini digunakan untuk menjelaskan suatu proses tentang pengoperasian JASP dalam pengolahan data statistik secara bertahap dan intepretasi output pengolahan data statistik.

\subsection{Latihan/Praktek atau tutorial}

Pada metode ini peserta mempraktekkan pengolahan data statistik dengan menggunakan program JASP sehingga mahasiswa terampil dalam pengolahan data statistik untuk meningkatkan kualitas penelitian dan karya ilmiah mahsiswa.

\subsection{Tahap Evaluasi}

Tahap evaluasi dilakukan untuk memberikan solusi dari permasalahan yang dihadapi oleh mahasiswa semester akhir FKIP Unmul untuk menunjang penulisan karya ilmiah atau penyusunan tugas akhir khususnya untuk mahasiswa Program Studi Pendidikan Jasmani, dalam rangka meningkatkan kemampuan mahasiswa dalam melakukan penelitian dan pengolahan data statistik dengan menggunakan program JASP. Tahap ini diukur melalui pemberian tes berupa Pre tes dan pos tes. 


\section{HASIL DAN PEMBAHASAN}

Kegiatan pelatihan pengolahan data penelitian berbasis software JASP dan SPSS bagi mahasiswa program studi Pendidikan jasmani Fakultas Keguruan dan Ilmu Pendidikan Universitas Mulawarman Kalimantan Timur ini dilaksanakan dengan metode daring atau online dan praktik aplikasi secara langsung, Pelatihan JASP dan SPSS berjalan lancar dan baik. Pelaksanaan kegiatan dilaksanakan tanggal 01 November 2021 dengan melalui zoom meeting mengingat masih dalam suasana pandemi COVID-19. Mahasiswa yang mengikuti pelatihan SPSS ini merupakan perwakilan dari semester VI program studi Pendidikan jasmani yang ada di Fakultas Keguruan dan Ilmu Pendidikan Universitas Mulawarman, dan mahasiswa dari program studi lain di bawah fakultas keguruan dan ilmu Pendidikan universitas mulawarman dimana setiap program studi bisa mengirim perwakilan untuk mengikuti kegiatan pelatihan, Mahasiswa yang yang mengikuti pelatihan SPSS terlebih dahulu mengisi daftar hadir. Dengan menggunakan google formular Setelah mengisi daftar hadir, mahasiswa diberi materi dalam bentuk softcopy untuk bisa di download dan di instal sebelum pelaksanaan dimulai seperti yang tampak pada Gambar 1 di bawah ini:

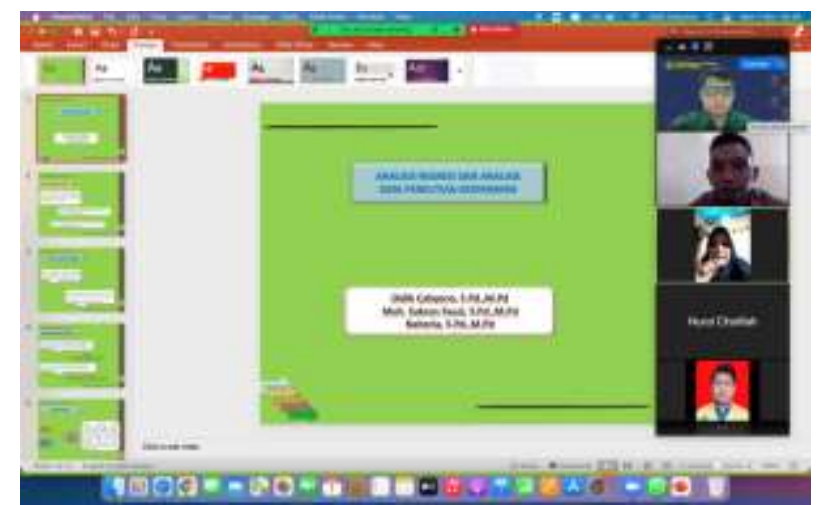

Gambar 1. Pelaksanaan pelatihan secara daring melalui zoom meeting

Dalam kegiatan pengabdian masyarakat ini tampak sebagian besar peserta mampu menjalankan analisis secara mandiri ketika diberikan tugas untuk menganalisis contoh data dalam bidang keolahragaan peserta dapat melakukan analisis secara mandiri ketika diberikan tugas untuk menganalisis deskriptif, uji persyaratan data, korelasi, uji t (dependent dan indepent). Fasilitator tidak menemukan ada peserta yang belum bisa mengoperasikan program JASP/SPSS ketika diminta untuk menganalisis data yang ada. Akan tetapi hasil yang berbeda didapat ketika masuk pada tugas analisis regresi. Para peserta merasa masih binggung dalam melakukan analisis dengan JASP dan SPSS. Hal ini terjadi karena peserta merasa bahwa analisis regresi lebih sukar dan kompleks bila dibandingkan dengan analisis yang sebelumnya. Itu sebabnya, fasilitator harus membimbing sebagian besar peserta pelatihan. Meskipun begitu, kegiatan pengabdian yang dilakukan tersebut tergolong berhasil karena peserta terlihat sangat antusias dan serius mengikuti kegiatan dari awal hingga akhir kegiatan.

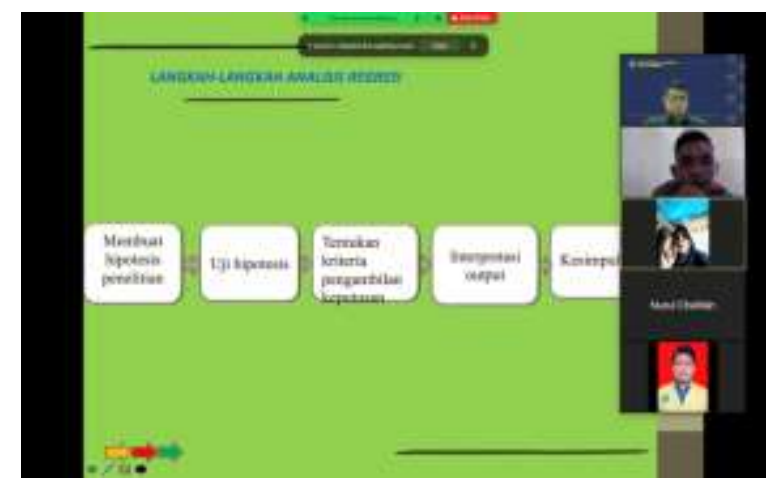

Gambar 2. Pemaparan materi JASP oleh pemateri pertama 
Pada tahap berikutnya, beberapa pertanyaan diajukan sebelum dan sesudah pelaksanaan oleh penulis untuk mengetahui tingkat pemahaman dari peserta guna mengetahui tingkat pemahaman dari peserta sekaligus untuk di gunakan sebagai laporan pengabdian kepada universitas.

Data hasil pre test dan post test pelatihan JASP dan SPSS.

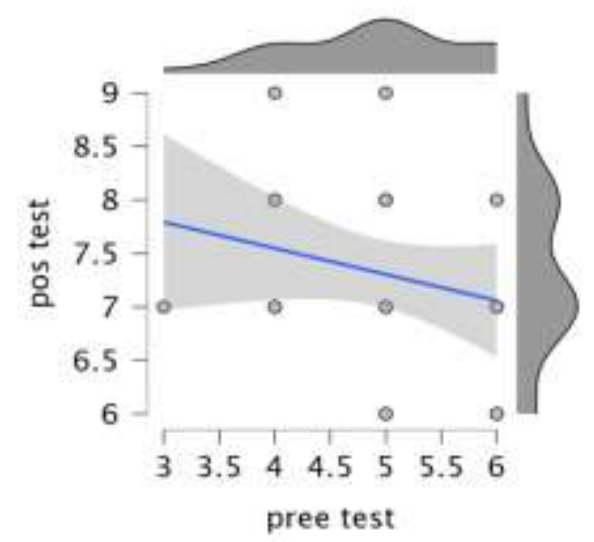

Gambar 3. Hasil Pre Test dan Post Test

Regresi Linear Sederhana digunakan untuk ....

16 jawaban

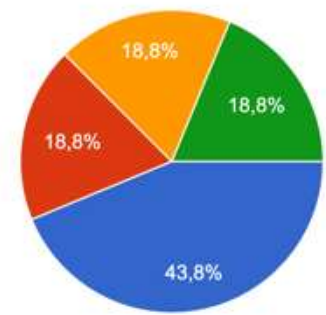

a. Untuk mengetahui pengaruh antara satu buah variabel bebas terhadap satu buah variabel terikat

b. Untuk mengetahui pengaruh antara satu buah variabel terikat terhadap satu buah variabel Bebas

c. Untuk mengetahui pengaruh antar variabel

- d. Untuk mengetahui apakah ada pengaruh pengaruh antar variabel

Gambar 4. Pre Test

Regresi Linear Sederhana digunakan untuk .... 9 jawaban

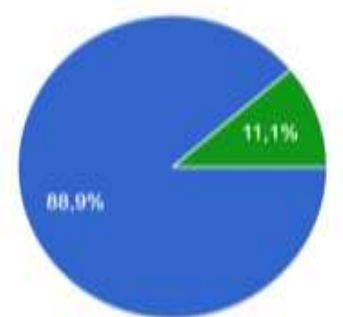

- a. Untuk mengetahui pengaruh antara satu buah variabel bebas terhadap satu buah variabel terikat

- b. Untuk mengetahui pengaruh antara satu buah variabel terikat terhadap satu buah variabel Bebas

- c. Untuk mengetahui pengaruh antar variabel

- d. Untuk mengetahui apakah ada pengaruh pengaruh antar variabel

Gambar 5. Post Test

Pertannyaan berikutnya yang diajukan adalah "Regresi linier sederhana digunakan untuk?". Terhadap pertanyaan tersebut, para peserta memberikan jawaban yang beragam namun kalau dikelompokan akan mengerucut pada empat hal seperti yang ada di gambar di atas bagian kanan. Dari gambar tersebut tampak bahwa peserta kegiatan pelatihan sebagian besar $(88,9 \%)$ mampu memahami dan menganalisa fungsi program JASP dan SPSS dengan baik.

\section{KESIMPULAN}

Berdasarkan hasil kegiatan pengabdian yang dilakukan maka dapat disimpulkan sebagai berikut: pertama, peserta pelatihan, terutama mahasiswa khususnya prodi Pendidikan jasmani, 
ternyata baru mengetahui program JASP dari pelatihan yang dilakukan; kedua, hanya sebagian kecil peserta yang dapat menginstal program JASP dan SPSS secara mandiri. Hal ini dikarenakan terdapat kendala dengan laptop yang dibawa oleh peserta, misalnya, ruang penyimpanan laptop yang sudah hampir penuh sehingga tidak dapat lagi diinstal dengan SPSS; ketiga, sebagian besar peserta pelatihan memahami dengan baik tentang sejarah dan fungsi JASP dan SPSS; keempat, sebagian besar peserta dapat melakukan analisis deskriptif, uji persyaratan data, korelasi, uji $t$ (dependent dan indepent) secara mandiri; kelima, hanya sebagian kecil peserta yang dapat melakukan analisis regresi dan anova; Saran yang dapat diajukan bertalian dengan hasil pengabdian tersebut, yaitu pelatihan sejenis lebih rutin dilakukan dan dengan melibatkan peserta yang lebih luas serta dilakukan di laboratorium komputer agar permasalahan terkait dengan masalah instalasi JASP dan SPSS tidak muncul lagi dalam penyusunan tugas akhir yang di hadapi mahasiswa tingkat akhir.

\section{UCAPAN TERIMA KASIH}

Ucapan Terima Kasih Penulis mengucapkan terima kasih kepada Fakultas Keguruan da Ilmu Pendidikan Universitas Mulawarman Kalimantan Timur yang telah memberi kesempatan dan dukungan financial terhadap pengabdian ini.

\section{DAFTAR PUSTAKA}

A. Hustia, A. Arifai, N. Afrilliana, and M. Novianty, "Pelatihan Pengolahan Data Statistik Menggunakan SPSS Bagi Mahasiswa," JMM J. Masy. Mandiri, vol. 5, no. 4, pp. 1-8, 2021.

D. J. Panjaitan, U. Muslim, and N. Al, "Pelatihan Pengolahan Data Statistik Dengan," no. 20, 2003.

F. T. Pasaribu, C. Multahadah, A. Febrianti, and R. W. Asiani, "Pelatihan Peningkatan Kemampuan Analisis Data Penelitian Menggunakan Software SPSS Bagi Pemuda RT. 14 Perumnas Aurduri Indah Kota Jambi," J. Karya Abdi Masy., vol. 2, no. 1, pp. 62-69, 2018, doi: 10.22437/jkam.v2i1.5432.

H. Syaleh, "Pelatihan Program Statistic Product and Service Solution (SPSS) bagi Mahasiswa dan Dosen Sekolah Tinggi Ilmu Ekonomi H. Agus Salim Bukittinggi," Community Engagem. Emerg. J., vol. 1, no. 1, pp. 14-21, 2020, doi: 10.37385/ceej.v1i1.42.

KBBI. 2012. Kamus Besar Bahasa Indonesia. Balai Pustaka. Jakarta

Nugroho, A. P. (2018). Statistik Untuk Ekonomi dan Sosial Menggunakan SPSS. Deepublish, Yogyakarta.

P. Zainal, "Pelatihan Pengolahan Data Penelitian Dengan Software SPSS Bagi Mahasiswa Lintas Perguruan Tinggi Abstrak," vol. 3, pp. 1-7, 2018.

Panjaitan, D. J., \& Firmansyah, F. (2018). Pelatihan Pengolahan Data Statistik Dengan Menggunakan SPSS. Prosiding Seminar Nasional Hasil Pengabdian,

R. Ismail and F. Safitri, "Peningkatan kemampuan analisa dan interpretasi data mahasiswa memalui pelatihan program SPSS," J. Masy. Mandiri, vol. 3, no. 2, pp. 148-155, 2019.

S. D. Simanjuntak and A. Usman, "Pelatihan SPSS pada Guru-Guru di Sekolah Dasar Negeri 173529 Tampahan," JPM (Jurnal Pemberdaya. Masyarakat), vol. 5, no. 2, pp. 486-491, 2020, doi: 10.21067/jpm.v5i2.3652.

Sugiyono, 2010. Statistika untuk Penelitian. Bandung : Alfabeta.

Suharsimi, A. (2006). metodelogi Penelitian. Yogyakarta: Bina Aksara,

T. Wijaya, "Peningkatan Kemampuan Pengolahan Data Melalui Pelatihan Statistik dan Aplikasi Program SPSS bagi Guru-Guru SMA di DIY," To Maega / J. Pengabdi. Masy., vol. 3, no. 1, p. 31, 2020, doi: 10.35914/tomaega.v3i1.293. 